\title{
Gender of children and social provisions as predictors of unplanned pregnancies in Pakistan: a cross-sectional survey
}

\author{
Sadiq Naveed ${ }^{1 \dagger}$, Usman Ghani Lashari ${ }^{2 \dagger}$, Ahmed Waqas ${ }^{3,4^{*}+}$ (D) Mariam Bhuiyan ${ }^{5}$ and Hafsa Meraj ${ }^{6}$
}

\begin{abstract}
Objective: Previous research indicates that attitudes to pregnancy and motherhood are influenced by social values, culture and religion. This study explores the relationship between social support and unwanted pregnancy among Pakistani women. This cross-sectional study was conducted at four teaching hospitals in Lahore in 2014.

Results: A total of 500 pregnant women who visited the hospitals' obstetrics and gynecology departments were asked to respond to a questionnaire consisting of respondents' characteristics and the Social Provisions Scale (SPS). Logistic regression analyzed the predictors of unplanned pregnancy. Unwanted pregnancies were more likely to occur among pregnant women from rural areas, with low scores on the SPS 'reassurance of worth' sub-scale, no history of contraceptive use, and who already had at least one son than those with no sons.
\end{abstract}

Keywords: Social support, Pregnancy, Family planning, Pakistan, Unwanted pregnancies, Motherhood, South Asia

\section{Introduction}

Unplanned pregnancies are defined as pregnancies that occur at inconvenient times in women's lives or pregnancies that are unwanted. They tend to cause hardship for families, and jeopardize the mental and physical health of millions of women and children worldwide. Problems include: late initiation of prenatal care, low birth-weight, child abuse and neglect, behavioral problems in children, lack of folic acid supplementation, low hemoglobin levels, and negative labor experience [1]. A close association has been found with antenatal depression and anxiety [2]. All of these factors increase neonatal care costs, and other costs related to long-term disability in women and babies [3]. Moreover, a frequent outcome of unintended pregnancy is induced abortion. In countries such as Pakistan where it is illegal, women resort to untrained midwives and untrained health professionals [4].

\footnotetext{
*Correspondence: ahmedwaqas1990@hotmail.com

†Sadiq Naveed, Usman Ghani Lashari and Ahmed Waqas contributed equally to the manuscript

${ }^{3} \mathrm{CMH}$ Lahore Medical College \& Institute of Dentistry, Lahore Cantt, Pakistan

Full list of author information is available at the end of the article
}

A number of studies have reported risk factors associated with unwanted pregnancies in different regions and cultures. They include socioeconomic disparities, lack of social support, the mother's age, parity and maternal behaviors such as smoking and alcohol consumption $[5,6]$. These risk factors are stable across cultures and found in different regions of the world. However, several culture-specific predictors of unwanted pregnancies have been reported in the literature. For instance, Hussain et al. found that the gender of older offspring is a major predictor of unwanted pregnancies in Pakistan [7]. Interestingly, in Southeast Asia, this factor also seems to play a role in guiding attitudes to unwanted pregnancies. Daughters are seen as inferior to sons, and consequently have poor access to healthcare and educational opportunities $[2,8]$. This sociocultural difference contributes to honor killings, the bride price, and dowry system, the lower status of female legal testimony, forced marriages, and the denial of a woman's right to have a career $[2,8]$. In contrast, sons are viewed as breadwinners and agents of the continuation of the family name.

Social support encompasses guidance and advice, help, care and self-esteem. It not only benefits the physical and mental health of the general populace, but also helps

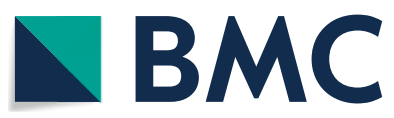

(c) The Author(s) 2018. This article is distributed under the terms of the Creative Commons Attribution 4.0 International License (http://creativecommons.org/licenses/by/4.0/), which permits unrestricted use, distribution, and reproduction in any medium, provided you give appropriate credit to the original author(s) and the source, provide a link to the Creative Commons license, and indicate if changes were made. The Creative Commons Public Domain Dedication waiver (http://creativecommons.org/ publicdomain/zero/1.0/) applies to the data made available in this article, unless otherwise stated. 
pregnant women to make informed decisions $[9,10]$. Perceived social support has also been shown to be a strong predictor of attitudes, practices and knowledge regarding unwanted pregnancies. In a similar context, studies have shown that social support plays a significant role in preventing the negative health consequences of pregnancy [2]. Support from the family, and society in general, helps a woman adjust to her new social role as a mother [11]. This becomes even more important in a patriarchal setting like Pakistan where information regarding wanted/ timed pregnancy is scarce, and attitudes to contraception are negative.

Unfortunately, there is a dearth of data exploring the factors associated with unintended pregnancies in Pakistan, thus, warranting this study. This study explores the factors associated with unintended pregnancies, with a focus on gender disparity, family systems, and societal support among Pakistani women.

\section{Main text \\ Methods}

This cross-sectional study was conducted in the obstetrics and gynecology departments of four teaching hospitals at Lahore, Pakistan, from February 2014 to June 2014. These hospitals are state-funded, and serve loweror lower-middle-income populations in surrounding areas. All pregnant women assessed as having low or lower middle income, who visited the departments for routine antenatal care were included. Women with major medical comorbidities and receiving inpatient treatment were excluded from current study. All participants gave written informed consent, and approval for the study was granted by the Research Ethics Review Committee of CMH Lahore Medical College, and the Institute of Dentistry, Lahore, Pakistan.

Data was collected conveniently by four, final-year medical students, using a pre-prepared questionnaire. Prior to data collection phase, these students received a 2-day interviewing and empathy skills workshop by trained psychologists, also ensuring a good inter-rate reliability. Participants provided demographic information, family structure and were asked to evaluate the state of their pregnancy, Hospital Anxiety and Depression Scale (HADS) and perceived levels of social support using the Social Provisions Scale (SPS). More details about the study design can be read elsewhere [2].

Perceived social support was assessed with Urdu version of the SPS [12], originally developed by Weiss [13]. This scale has been cross-culturally validated among the Pakistani population, and has been shown to have excellent psychometric properties [12]. Internal consistency was very high in the present study sample (Cronbach's alpha $=0.92$ ). It consists of 24 questions describing different characteristics of participants' social support system. It assesses responses on a 4-point response; 1 (strongly disagree) to 4 (strongly agree).

According to Weiss [13], social support is a multidimensional concept consisting of six "provisions", which may be obtained from relationships with others [13]. It is generally believed that individuals require all of them to feel adequately supported [14]. The six provisions as assessed with SPS are: (a) attachment: emotional closeness from which one derives a sense of security; (b) social integration: a sense of belonging to a group of people who share common interests, recreational activities and concerns; (c) reassurance of worth: acknowledgment of one's competence and skills; (d) reliable alliance: the assurance that one can count on others for assistance under any circumstances; (e) guidance: advice and information; and (f) opportunities to nurture: the sense that others rely upon one for their well-being $[13,14]$.

Post-hoc power analysis with GPower (v 3.1.7) revealed that a power of $84 \%$ was achieved using following parameters: sample size of 500, alpha (0.05), $\mathrm{R}^{2}$ with other covariates (0.04), probability of unplanned pregnancies with high social support (30\%) and low social support levels (43\%).

All data were analyzed in SPSS (version 20). Categorical data were presented as frequencies, and quantitative data as means (SD). Association between parity among mothers and status of pregnancy was explored using point-biserial correlation. Partial correlation was used to assess association between SPS scores and status of pregnancy, after controlling for age of the respondents. Logistic regression analyzed predictors of unplanned pregnancy. Education, background (rural vs urban), household income (low vs high), number of daughters and sons, and scores on Social Provisions Scale were entered as covariates in the regression model. Prior to running the regression analysis, Box-Tidwell (1962) test was used to ascertain the linearity of the continuous variables with respect to the logit of the dependent variable. An alpha value $<0.05$ was considered significant.

\section{Results}

The final sample consisted of 500 respondents. The mean age was 27.41 (5.65), most were from rural areas, from a low socioeconomic class, and had not completed high school. The majority reported that their current pregnancy was unplanned (365, 73\%). A total of 276 (55.2\%) of women had a prior history of contraceptive use. An analysis of HADS scores showed that a high percentage of women suffered from antenatal anxiety $(245,49 \%)$ and depression $(159,31.8 \%)$. The demographic characteristics of respondents and their mean (SD) SPS scores are presented in Table 1. Our findings related to antenatal 
Table 1 Demographic characteristics and SPS scores for pregnant women in Lahore $(n=500)$

\begin{tabular}{|c|c|c|c|}
\hline Variable & Frequency (n) & Percentage (\%) & Mean (SD) \\
\hline \multicolumn{4}{|l|}{ Pregnancy } \\
\hline Planned & 135 & 27 & \\
\hline Unplanned & 365 & 73 & \\
\hline \multicolumn{4}{|l|}{ Education } \\
\hline Illiterate & 85 & 17 & \\
\hline Literate & 415 & 83 & \\
\hline \multicolumn{4}{|l|}{ Background } \\
\hline Rural & 182 & 36.4 & \\
\hline Urban & 318 & 63.6 & \\
\hline \multicolumn{4}{|c|}{ Monthly household income } \\
\hline$\leq 81.11$ USD & 148 & 29.6 & \\
\hline$>81.11$ USD & 352 & 70.4 & \\
\hline \multicolumn{4}{|l|}{ Having daughters } \\
\hline Yes & 236 & 47.2 & \\
\hline No & 264 & 52.8 & \\
\hline \multicolumn{4}{|l|}{ Having sons } \\
\hline Yes & 278 & 55.6 & \\
\hline No & 222 & 44.4 & \\
\hline \multicolumn{4}{|c|}{ Used family planning previously } \\
\hline Yes & 224 & 44.8 & \\
\hline No & 276 & 55.2 & \\
\hline \multicolumn{4}{|l|}{ Parity } \\
\hline Primipara & 160 & 32.0 & \\
\hline 1 child & 122 & 24.4 & \\
\hline 2 children & 90 & 18.0 & \\
\hline$\geq 3$ children & 128 & 25.6 & \\
\hline Social Provisions Scale & & & $72.32(12.20)$ \\
\hline Attachment & & & $11.83(2.43)$ \\
\hline Social integration & & & $11.85(2.77)$ \\
\hline Reassurance of worth & & & $11.95(2.69)$ \\
\hline Reliable alliance & & & $12.48(2.39)$ \\
\hline Guidance & & & $12.29(2.41)$ \\
\hline Nurturance & & & $11.91(2.46)$ \\
\hline
\end{tabular}

anxiety and depression in this sample can be read elsewhere [2] (Additional file 1).

Parity among mothers was associated positively with unplanned pregnancies $(\mathrm{r}=0.19, p<0.001)$ and insignificantly with social support $(\mathrm{r}=-0.04, p>0.05)$. The partial correlations showed that unplanned pregnancy was negatively associated with the total score on the SPS scale $(\mathrm{r}=-0.19, p<0.001)$, which persisted even after controlling for the age of the respondent $(\mathrm{r}=-0.19, p<0.001)$.

The logistic regression model was statistically significant $(p<0.001)$. Hosmer and Lemeshow Chi square statistics was non-significant $\left(p=0.335, \chi^{2}=9.08\right)$. Logistic regression predicted $75.6 \%$ of the model correctly, unplanned pregnancies 93.4\%, planned pregnancies (27.4\%), and explaining $21.1 \%$ of variance in unwanted pregnancies. Women from rural areas had higher odds of having an unplanned pregnancy than their urban counterparts. Low scores on both reassurance and nurturance subscale exhibited an increased likelihood of unplanned pregnancy among the participants. The history of use of contraceptives halved the likelihood of unplanned pregnancies, however, those pregnant women who had one or more sons exhibited higher odds of unplanned pregnancies than their counterparts. On the other hand, education level, household income, having daughters, total number of children, attachment, social integration, reliable alliance, and guidance were insignificant predictors (Table 2).

\section{Discussion}

Our study found a high prevalence of unwanted pregnancies among Pakistani women who lived in rural areas, scored low on the 'reassurance of worth' SPS subscale, had no history of using contraceptives, and already had sons. Our findings are comparable with statistics reported in Karachi (38\%) and other developing and third-world countries such as Brazil $(\mathrm{n}=55.8 \%)$, but are much higher than the developed world, where estimates are comparatively low-for example $27 \%$ in Canada [4, $15,16]$.

Our study showed that unplanned pregnancies are consistent with a lack of social support, particularly the 'reassurance of worth' SPS subscale. Our findings are in concordance with Shahry et al. who reported that women with unwanted pregnancies exhibit low social support and self-efficacy [17]. Social support is an important buffer in stressful situations, such as during an unintended pregnancy, the lack of which may lead to a variety of psychopathologies such as perinatal anxiety and depression and deleterious health consequences for the fetus $[2,9,13]$. These trends have also been demonstrated among British women with unplanned pregnancies who reported lower levels of perceived support and less contact with friends and family, leading to feelings of isolation and negative attitudes toward their pregnancy [18].

Reassurance of worth is one of the six provisions described by Weiss, and refers to an acknowledgment of one's competence and skills, and an admiration of one's talents and abilities [13]. It is interesting to note that, according to Weis, reassurance of worth is often provided by co-workers [13]. This is particularly relevant in the Pakistan socio-cultural setting where, in some traditional families, working women are stigmatized. The home is considered the appropriate place for women, and their role is to be an obedient wife and a loving mother. Several studies have found that Muslim women tend to place 
Table 2 Predictors of unplanned pregnancy in pregnant females $(n=500)$

\begin{tabular}{|c|c|c|c|c|c|c|c|}
\hline \multirow[t]{2}{*}{ Variables } & \multirow[t]{2}{*}{ Subcategories } & \multirow[t]{2}{*}{ B } & \multirow{2}{*}{$\begin{array}{l}\text { Standard error } \\
\text { in B }\end{array}$} & \multirow[t]{2}{*}{$p$} & \multirow[t]{2}{*}{ Odds ratio (OR) } & \multicolumn{2}{|c|}{$95 \% \mathrm{Cl}$ for OR } \\
\hline & & & & & & Lower & Upper \\
\hline \multirow[t]{2}{*}{ Education } & Literate & -0.295 & 0.303 & 0.330 & 1 & & \\
\hline & Illiterate & & & & 0.744 & 0.411 & 1.348 \\
\hline \multirow[t]{2}{*}{ Background } & Rural & 0.968 & 0.276 & $<0.001$ & 1 & & \\
\hline & Urban/semi-urban & & & & 2.633 & 1.533 & 4.522 \\
\hline \multirow[t]{2}{*}{ Household income } & Low & 0.264 & 0.266 & 0.322 & 1 & & \\
\hline & High & & & & 1.302 & 0.772 & 2.194 \\
\hline \multirow[t]{2}{*}{ Having daughters } & Yes & -0.033 & 0.287 & 0.908 & 1 & & \\
\hline & No & & & & 0.968 & 0.551 & 1.698 \\
\hline \multirow[t]{2}{*}{ Having sons } & Yes & 0.701 & 0.292 & 0.016 & 1 & & \\
\hline & No & & & & 2.02 & 1.137 & 3.571 \\
\hline \multirow[t]{2}{*}{ Total children } & $\leq 1$ & -0.415 & 0.362 & 0.251 & 1 & & \\
\hline & $\leq 2$ & & & & 0.660 & 0.325 & 1.341 \\
\hline \multirow[t]{2}{*}{ Used contraceptives } & No & 0.497 & 0.249 & 0.046 & 1 & & \\
\hline & Yes & & & & 1.644 & 1.009 & 2.678 \\
\hline Attachment & & 0.117 & 0.080 & 0.146 & 1.124 & 0.960 & 1.315 \\
\hline Social integration & & -0.074 & 0.054 & 0.173 & 0.929 & 0.835 & 1.033 \\
\hline Reassurance of worth & & 0.133 & 0.056 & 0.018 & 1.143 & 1.023 & 1.276 \\
\hline Reliable alliance & & -0.017 & 0.076 & 0.819 & 0.983 & 0.846 & 1.141 \\
\hline Guidance & & 0.050 & 0.085 & 0.556 & 1.051 & 0.890 & 1.242 \\
\hline Nurturance & & -0.101 & 0.060 & 0.089 & 0.904 & 0.804 & 1.016 \\
\hline Constant & & -2.397 & 0.812 & 0.003 & 0.091 & & \\
\hline
\end{tabular}

Cox and Snell $R^{2}=14.5 \%$, Negelkerke $R^{2}=21.1 \%$

a very high value on motherhood, more so than women from other religious and cultural backgrounds $[19,20]$. Therefore, in the context of Pakistan, reassurance of worth may also be derived from the home environment.

According to Grav et al. emotional support has been found to be particularly important for women [9]. This explains why women with a lack of social support tend to exhibit adverse emotional symptoms. In eastern societies, there is a strong cultural taboo against pregnancies in certain groups, notably unmarried women. Such pregnancies are likely to be unplanned, there is very little social support, and the mothers are castigated by the community, leading to a lack of reassurance of worth public and internalized stigmatization and social discrimination [21]. Affirming the role of women as mothers and wives, and empowering them to make their own decisions may lead to a lower prevalence of unplanned pregnancies.

Our analysis revealed that women with a history of using contraceptives were less likely to have an unplanned pregnancy. According to the Demographic and Health Survey conducted by The United Nations Children's Emergency Fund (UNICEF) in 2015, Pakistan has the second-lowest rate of contraceptive use among South Asian countries, after Afghanistan [22]. In Muslim cultures, motherhood is considered a major milestone, and the fulfillment of a woman's destiny [23, 24]. Hence it is unsurprising that women are hesitant to use contraception. There is a need to increase awareness of contraceptive use, and improve knowledge of the different methods of contraception, which should be coupled with giving women greater autonomy to make decisions in this area [25].

Our analysis found that women from rural areas were more likely to have unplanned pregnancies than their urban counterparts. This may be because gender discrimination is more evident in rural communities, where women have less autonomy and are more likely to succumb to superstition and traditional values regarding pregnancy [26]. Additionally, our analysis revealed that urban women have higher rates of contraceptive use than those living in rural areas, which also contributes to their lower number of unplanned pregnancies.

Another finding was that unplanned pregnancies are significantly associated with the gender of older children. Mothers who already had sons were more likely to have unplanned pregnancies. Our results are consistent with the statistics reported by Hussain et al. who evaluated the role of the gender of older offspring in reproductive intentions and, thus, the behavior of Pakistani women [7]. 
This is relevant in the South Asian region, where reproduction is an integral part of patriarchal and heteronormative family systems-sons are seen as the carriers of the family name and breadwinners, and are therefore preferred to their female counterparts. We opine that deterrence to the use of contraceptives because of increasing number of sons among families occurs for a multitude of reasons. One of these reasons include financial security of respective parents in old age, as well as assistance in bringing up the younger offspring. Moreover, elder brothers usually bear the responsibility of assisting parents in collecting dowry for the younger sisters.

However, unlike Hussain et al. our study did not find that already having daughters was significantly associated with status of the pregnancy [7]. This is an encouraging trend, and reflects a sociocultural change that suggests a better attitude toward having daughters. The transition in family systems, women's agency and fertility has been documented in a number of studies. For instance, Buzdar and Ali, noted a rise in positive attitudes toward educating daughters, despite major disparities in infrastructure and access to schools, among the tribal populace of Dera Ghazi Khan in Punjab, Pakistan [27].

In our study, education was not significantly associated with the number of unplanned pregnancies. It is usual to expect that better education is consistent with a decrease in unplanned pregnancies. However, it is important to note that, unlike more developed countries, most schools in South Asia do not teach reproductive health [28]. In fact, such education is often considered a taboo, and even educated women may lack knowledge [28].

\section{Limitations}

This study has several limitations and therefore, the results should be interpreted with caution. Its crosssectional nature limits any inferences about causality and temporality between unplanned pregnancy and the associated factors. Convenience sampling and the lack of data for comparison with control groups limits the generalizability of the results. The hospital in which the data was sampled catered mainly to lower- and lower-middle income groups. Therefore, this bias might not reflect the prevalence, attitudes, and factors affecting unplanned pregnancies in the upper socioeconomic classes of Pakistan.

\section{Additional file}

Additional file 1. Social provisions, anxiety and depression during pregnancy. This dataset contains all variables pertaining to the publication including demographic characteristics, family composition, social support, anxiety and depression among pregnant women in Pakistan.
Abbreviations

SPS: Social Provisions Scale; HADS: Hospital Anxiety and Depression Scale.

\section{Authors' contributions}

SN, AW conceived the study, collected data and performed statistical analysis. UGL drafted the manuscript and contributed to data analysis. MB, HM participated in the study design, helped to draft the manuscript and revised it critically. All authors read and approved the final manuscript.

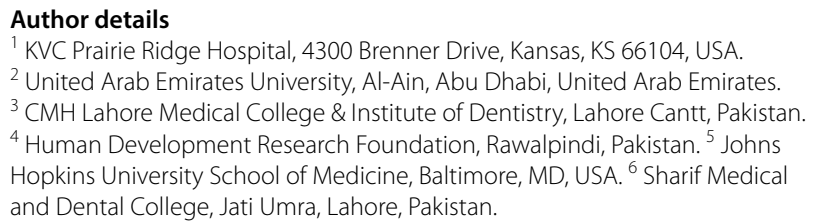

\section{Acknowledgements}

We would like to thank Elaine Seery (Author AID in the Eastern Mediterranean) for improving the use of English in the manuscript.

\section{Competing interests}

The authors declare that they have no competing interests.

\section{Availability of data and materials}

A confidentiality agreement with participants prevents us from sharing the data.

\section{Consent for publication}

Not applicable.

\section{Ethics approval and consent to participate}

All participants gave written informed consent, and approval for the study was granted by the Research Ethics Review Committee of CMH Lahore Medical College, and the Institute of Dentistry, Lahore, Pakistan.

\section{Funding}

There was no funding for this study.

\section{Publisher's Note}

Springer Nature remains neutral with regard to jurisdictional claims in published maps and institutional affiliations.

Received: 4 May 2018 Accepted: 9 August 2018

Published online: 14 August 2018

\section{References}

1. Yannikkerem E, Ay S, Piro N. Planned and unplanned pregnancy: effects on health practice and depression during pregnancy. J Obstet Gynaecol Res. 2013;39:180-7.

2. Waqas A, Raza N, Lodhi HW, Jamal M, Muhammad Z, Rehman A. Psychosocial factors of antenatal anxiety and depression in Pakistan: is social support a mediator? PLoS ONE. 2015;10:e0116510.

3. Le HH, Connolly MP, Bahamondes L, Cecatti JG, Yu J, Hu HX. The burden of unintended pregnancies in Brazil: a social and public health system cost analysis. Int J Womens Health. 2014;6:663-70.

4. Filha MM, Ayers S, da Gama SGN, Leal MDC. Factors associated with postpartum depressive symptomatology in Brazil: the Birth in Brazil National Research Study, 2011/2012. J Affect Disord. 2016;194:159-67. https://doi. org/10.1186/s12978-016-0227-8.

5. A Langer. El embarazo no deseado: impacto sobre la salud y la sociedad en América Latina y el Caribe el embarazo no deseado: conceptos y situación regional. Rev Panam Salud Publica/Pan Am J Public Health. 2002;11:192-205.

6. Finer LB, Zolna MR. Unintended pregnancy in the United States: incidence and disparities, 2006. Contraception. 2011:84:478-85.

7. Hussain R, Fikree FF, Berendes HW. The role of son preference in reproductive behaviour in Pakistan. Bull World Health Organ. 2000;78:379-88. 
8. Alam A. Impact of gender discrimination on gender development and poverty alleviation. Sarhad J Agric. 2011;27:329-39.

9. Grav S, Hellzèn O, Romild U, Stordal E. Association between social support and depression in the general population: the HUNT study, a crosssectional survey. J Clin Nurs. 2012:21:111-20.

10. Biaggi A, Conroy S, Pawlby S, Pariante C. Identifying the women at risk of antenatal anxiety and depression: a systematic review. J Affect Disord. 2016;191:62-77.

11. Arnold-Baker C. How becoming a mother involves a confrontation with existence: an existential-phenomenological exploration of the experience of early motherhood. London: Middlesex University; 2015.

12. Rizwan M, Syed N. Urdu translation and psychometric properties of social provision scale. Int J Educ Psychol Assess. 2010;4:33-47.

13. Weiss R. The provisions of social relationships. Doing unto others. 1974. http://ci.nii.ac.jp/naid/10007621399/. Accessed 11 May 2017.

14. Cutrona C. Social support and adaptation to stress by the elderly. Psychol Aging. 1986;1:47-54.

15. Oulman E, Kim THM, Yunis K, Tamim H. Prevalence and predictors of unintended pregnancy among women: an analysis of the canadian maternity experiences survey. BMC Pregnancy Childbirth. 2015:15:260.

16. Habib MA, Raynes-Greenow C, Nausheen S, Soofi SB, Sajid M, Bhutta ZA, et al. Prevalence and determinants of unintended pregnancies amongst women attending antenatal clinics in Pakistan. BMC Pregnancy Childbirth. 2017;17:156. https://doi.org/10.1186/s12884-017-1339-z.

17. Shahry P, Kalhori SRN, Esfandiyari A, Zamani-Alavijeh F. A comparative study of perceived social support and self-efficacy among women with wanted and unwanted pregnancy. Int J Commun Nurs Midwifery. 2016;4:176-85.

18. Barton K, Redshaw M, Quigley MA, Carson C. Unplanned pregnancy and subsequent psychological distress in partnered women: a cross-sectional study of the role of relationship quality and wider social support. BMC Pregnancy Childbirth. 2017;17:44. https://doi.org/10.1186/s1288 4-017-1223-x

19. Razina N. Attitudes to motherhood in different cultures. Psychol Russia. 2014:7:93-104

20. Raza N, Waqas A, Jamal M. Post-operative anxiety, depression and psychiatric support in patients undergoing hysterectomy: a cross sectional survey. J Pak Med Assoc. 2015;65:443-5.

21. Hall K, Kusunoki Y, Gatny H, Barber J. Social discrimination, stress, and risk of unintended pregnancy among young women. J Adolesc Health. 2015;56:330-7. http://www.sciencedirect.com/science/article/pii/S1054 139X14007393. Accessed 16 May 2017.

22. UNICEF. Demographic and Health Surveys. ICF International. Multiple Indicator Cluster Survey (Datasets). 2015.

23. Hollos M, Larsen U. Motherhood in sub-Saharan Africa: the social consequences of infertility in an urban population in northern Tanzania. Cult Health Sex. 2008;10:159-73.

24. Obeidat H, Hamlan A, Callister L. Missing motherhood: Jordanian women's experiences with infertility. Adv Psychiatry. 2014;2014:241075.

25. Hakim A, Salway S, Mumtaz Z. Women's autonomy and uptake of contraception in Pakistan. Asia Pac Popul J. 2003;18:63-81.

26. Sathar Z, Kazi S, Zaidi S. Women autonomy and the onset of fertility change in Pakistan: the significance of gender inequality across communities. In: Annual meeting of the population association of America New Orleans Louisiana; 1996

27. Buzdar M, Ali A. Parents' Attitude toward daughters' education in tribal area of Dera Ghazi Khan (Pakistan). Turk Online J. 2011;2:16-23.

28. Svanemyr J, Baig Q, Chandra-Mouli V. Scaling up of life skills based education in Pakistan: a case study. Sex Educ. 2015;15:249-62.
Ready to submit your research? Choose BMC and benefit from:

- fast, convenient online submission

- thorough peer review by experienced researchers in your field

- rapid publication on acceptance

- support for research data, including large and complex data types

- gold Open Access which fosters wider collaboration and increased citations

- maximum visibility for your research: over 100M website views per year

At BMC, research is always in progress.

Learn more biomedcentral.com/submissions 